\title{
ANN Based Optimized AHU Discharge Air Temperature Control of Conventional VAV System for Minimized Cooling Energy in an Office Building
}

\author{
Jong Man Lee ${ }^{1}$, Won Hee Kang ${ }^{1}$, and Kwang Ho Lee ${ }^{2, *}$ \\ ${ }^{1}$ Graduate School, Hanbat National University, San 16-1, Dukmyung-Dong, Yuseong-Gu, Daejeon 305-719, Korea \\ ${ }^{2}$ Department of Architectural Engineering, Hanbat National University, San 16-1, Dukmyung-Dong, Yuseong-Gu, Daejeon 305-719, \\ Korea
}

\begin{abstract}
In most conventional forced-air systems, the guidelines for the air handling unit(AHU) discharge air temperature(DAT) are not fully established and thus AHU DAT are constantly fixed to a particular setpoint, regardless of dynamic changes of operating variables. In this circumstance, this study aimed at developing a control algorithm that can operate a conventional VAV system with optimal set-points for the AHU DAT. Three-story office building was modeled using co-simulation technique between EnergyPlus and Matlab via BCVTB(Building Controls Virtual Test Bed). In addition, artificial neural network(ANN) model, which was designed to predict the cooling energy consumption for the upcoming next time-step, was embedded into the control algorithm using neural network toolbox within Matlab. By comparing the predicted energy for the different set-points of the AHU DAT, the control algorithm can determine the most energyeffective AHU DAT set-point to minimize the cooling energy. The results showed that the prediction accuracy between simulated and predicted outcomes turned out to have a low coefficient of variation root mean square error (CvRMSE) value of approximately 24\%. In addition, the predictive control algorithm was able to significantly reduce cooling energy consumption by approximately $10 \%$, compared to a conventional control strategy of fixing AHU DAT to $14^{\circ} \mathrm{C}$.
\end{abstract}

\section{Introduction}

According to the World Meteorological Organization's Greenhouse Gas Bulletin in 2017, the average global atmospheric carbon dioxide level in 2016 was $403.3 \mathrm{ppm}$. What is more problematic is that the concentrations of nitrous oxide and methane, which accelerate global warming more than carbon dioxide, are also increasing day by day.[1] As a result, recognizing the worldwide severity, we have agreed to reduce greenhouse gas emissions, including carbon dioxide, through the 2015 Paris Climate Change Convention.[2] In Korea, building energy conservation projects such as energy saving plan, building energy efficiency class certification, and zero energy building are being carried out.[3] However, there is no energy saving guideline for the heat pump control that is applied to most office buildings. In the case of office buildings in Korea, cooling energy accounts for a large portion of annual energy consumption. Moreover, about $57 \%$ of the cooling energy uses electricity, which causes greenhouse gas increase.[4] Therefore, this study proposes a new control guideline for AHU(Air Handling Unit) DAT(Discharge Air Temperature) in heat pump. In the case of AHU, it is mostly fixed control at a specific temperature regardless of load conditions. Therefore, this study adopted ANN(Artificial Neural Network)-based control method which is increasingly applied to solve complex problems in various fields due to its ability to learn and analyze mapping relationships including nonlinear phenomena. ANN enables more accurate predictions than the mathematically analytical model through its adaptability to external changes. In addition, it is able to predict the optimal variables for optimal control to implement an accurate and efficient control. Based on this, this study aims to analyze cooling energy reduction effect during summer according to AHU DAT optimal control by using ANN model.

\section{Research Method}

\subsection{Simulation Overview}

This study used EnergyPlus, a program developed by the U.S. Department of Energy based on the combined advantages of BLAST and DOE-2.[5] In addition, MATLAB / Simulink, which provides the Neural Network Tool Box function, was used to implement ANN. We use the BCVTB program to simulate real - time interworking of these two programs. This enables real-time simulation

\footnotetext{
* Corresponding author: kwhlee@hanbat.ac.kr
} 
of EnergyPlus and MATLAB / Simulink, enabling more accurate analysis.

\subsection{Simulation Model}

In this study, the size of the target building for simulation is $52 \mathrm{~m} \mathrm{X} 35 \mathrm{~m}\left(1,820 \mathrm{~m}^{2}\right)$, and the floor-to-floor height of the 3-story office building is $4 \mathrm{~m}$. The building to be analyzed was selected as a virtual office building with a WWR(window-to-wall ratio) of $30 \%$.

\subsection{Simulation Condition}

This study used the meteorological data of Incheon basically provided by EnergyPlus, and the air conditioning system is an AHU-based conventional VAV system consisting of a hot water coil supplied with hot water from the boiler and a chilled water coil supplied with chilled water from the chiller. Double glazing glass (6mm glass $+13 \mathrm{~mm}$ air $+6 \mathrm{~mm}$ glass) was applied to the windows. The frame was assumed as an aluminum window frame with a width of $0.0572 \mathrm{~m}$ and a projection of $0.0254 \mathrm{~m}$ from the glass window. The composition of the modeling and the material properties refer to ASHRAE Standard 90.1. Indoor cooling set temperature is set at $26{ }^{\circ} \mathrm{C}$ and the internal heat gain conditions are shown in Table 1. Figure 1 shows the internal heat gain schedule for weekdays and HVAC system was set to operate from 5:00 to 19:00.

Table 1. Internal heat gain conditions

\begin{tabular}{|c|c|c|}
\hline Type & Value & Fraction Radiant \\
\hline Occupancy & $9.3 \mathrm{~m}^{2} /$ person & 0.367 \\
\hline Light & $9.1 \mathrm{~W} / \mathrm{m}^{2}$ & 0.32 \\
\hline Equipment & $14.4 \mathrm{~W} / \mathrm{m}^{2}$ & 0.5 \\
\hline
\end{tabular}
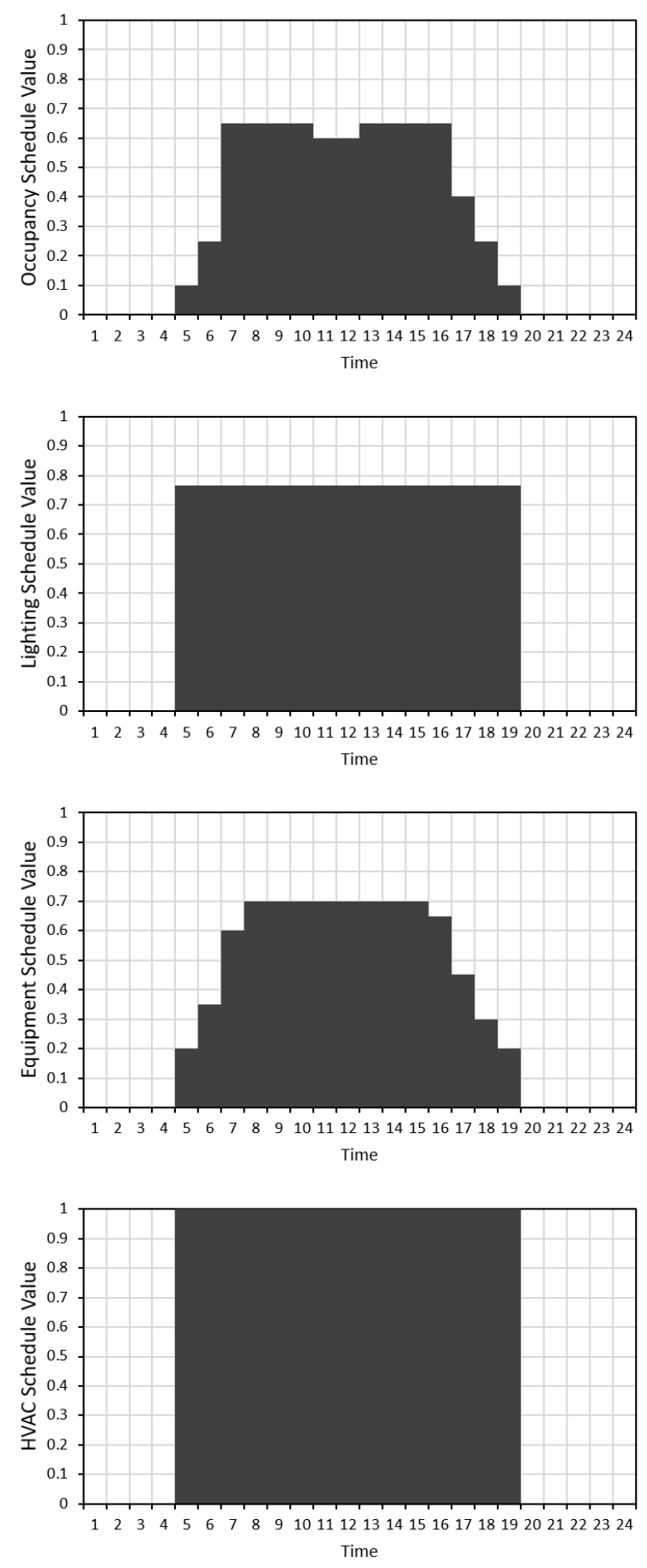

Figure 1. Occupancy, Lighting, Electric Equipment, and HVAC schedules

\subsection{Co-simulation Platform}

The purpose of this study is to minimize the total energy consumption which combined the electrical energy consumption of AHU supply fan, relief fan, two chillers, cooling tower, chilled water pump, and condenser water pump through the optimal control of AHU DAT by using ANN model. This study established a co-simulation between EnergyPlus and MATLAB through BCVTB platform in order to implement this. The modeling of the 
building and system for simulation was implemented through EnergyPlus using the ExternalInterface and ExternalInterface:Schedule Objects for co-simulation. The ANN model was implemented by using neural network toolbox function included in the MATLAB program, and real-time data exchange of EnergyPlus and MATLAB through BCVTB platform is shown in Table 2. In addition, TimeStep was set to 5 minute intervals for the accuracy of co-simulation. When exchanging data, ANN model implemented by MATLAB stopped the artificial neural network learning except for HVAC operating hours according to HVAC system schedule and AHU DAT was fixed at $18^{\circ} \mathrm{Cduring}$ the weekend. In addition, AHU DAT was fixed at $18^{\circ} \mathrm{C}$ for time periods when HVAC system was not operating on weekdays, same as the weekends.

Table 2. Data exchange list

\begin{tabular}{|c|c|}
\hline EnergyPlus $\rightarrow$ MATLAB & $\begin{array}{c}\text { MATLAB } \rightarrow \\
\text { EnergyPlus }\end{array}$ \\
\hline $\begin{array}{c}\text { Outdoor Air Dry-bulb } \\
\text { Temperature }\left[{ }^{\circ} \mathrm{C}\right]\end{array}$ & \multirow{5}{*}{$\begin{array}{l}\text { AHU Discharge Air } \\
\text { Temperature }\left[{ }^{\circ} \mathrm{C}\right]\end{array}$} \\
\hline $\begin{array}{c}\text { Outdoor Air Relative } \\
\text { Humidity [\%] }\end{array}$ & \\
\hline $\begin{array}{c}\text { Diffuse Solar Radiation } \\
\text { Rate per Area }[\mathrm{W} / \mathrm{m} 2]\end{array}$ & \\
\hline $\begin{array}{l}\text { Direct Solar Radiation } \\
\text { Rate per Area [W/m2] }\end{array}$ & \\
\hline $\begin{array}{c}\text { Cooling Coil } \\
\text { Total Cooling Rate [W] }\end{array}$ & \\
\hline
\end{tabular}

\subsection{Predictive ANN Model Development}

In order to develop ANN model, this study used neural network toolbox function embedded in MATLAB. As shown in Figure 2, the process for developing the total energy consumption prediction model according to AHU DAT is composed of 3 steps. The first step determines the input layer, hidden layer, and output layer of the initial model and the configuration and learning method of each neuron. In the second step, the initial model is optimized and determines the number of hidden layers and hidden neurons in which the prediction model can yield the most accurate result values. By applying CV(RMSE) (Coefficient of Variation of the Root Mean Squared Error), which is a statistical concept of viewing the overall accuracy of the predicted values, the number of hidden layers and hidden neurons when CV(RMSE) value is the lowest was determined as the optimal ANN model. The $\mathrm{CV}(\mathrm{RMSE})$ value is determined to be a reliable value when it is below $30 \%$ of the hourly data standard given in ASHRAE Guideline 14, and Equation 1 and Equation 2 show how to calculate RMSE and CV(RMSE), respectively.[6] Finally, the third step secures the applicability through analyzing the performance of the optimized ANN model, and verifies the stability and accuracy of the prediction by comparing the results predicted by ANN model with EnergyPlus simulation results.

\section{Initial model development $\checkmark$ Assign Input, Hidden, Output neuron \\ $\checkmark$ Selection of structure and learning method}

\section{Model optimization $\checkmark$ CV(RMSE) according to Hidden layer, Hidden neuron}

\section{Performance evaluation $\checkmark$ Evaluate prediction accuracy}

Figure 2. ANN model development steps

Where,

$$
\begin{gathered}
R M S E=\sqrt{\frac{\sum(S-M)_{\text {interval }}^{2}}{N_{\text {interval }}}} \\
C V(R M S E)=\frac{R M S E_{\text {period }}}{A_{\text {period }}} \\
A_{\text {period }}=\sqrt{\frac{\sum_{\text {period }} M_{\text {interval }}}{N_{\text {interval }}}}
\end{gathered}
$$

\section{$S$ : ANN model prediction value}

$M$ : Actual measurement value

$N_{\text {interval }}$ : Number of actual measurement values

The initial ANN model to be developed and used in this study consists of 6 input neurons as shown in Figure 3 , and the parameters applied are shown in Table 3. In the initial ANN model, the number of hidden layers and hidden neurons was randomly set to 1 hidden layer and 10 hidden neurons. The learning data for the initial ANN model was built using EnergyPlus and data from 07:00 to 19:00 excluding weekends from June 1 to August 31 were collected and used. In terms of the simulation conditions, AHU DAT was increased by $1^{\circ} \mathrm{C}$ from $12^{\circ} \mathrm{C}$ to $18^{\circ} \mathrm{C}$ to derive data for the input neuron along with parameters and total energy consumption, which is the output neuron result value. The output neuron is total energy consumption, which is a total sum of the electrical energy 
consumption of AHU Supply Fan, Relief Fan, Two Chillers, Cooling Tower, Chilled Water Pump, and Condenser Water Pump. As for transfer functions, the Tangent-Sigmoid and Pure-Linear methods were used for the hidden and output layer neurons, respectively. In addition, the Levenberg-Marquardt algorithm was used for the learning process of ANN model. The LevenbergMarquardt algorithm appears as the function trainlm in MATLAB, which is the basic training function for wardnet feeds. This method tends to be less efficient for large networks, as more memory and computation time are required. In addition, trainlm works better on function fitting problems such as non-linear regression than pattern recognition problems [7]. The learning rate of the initial model was set to 0.3 and the momentum was set to 0.3 .

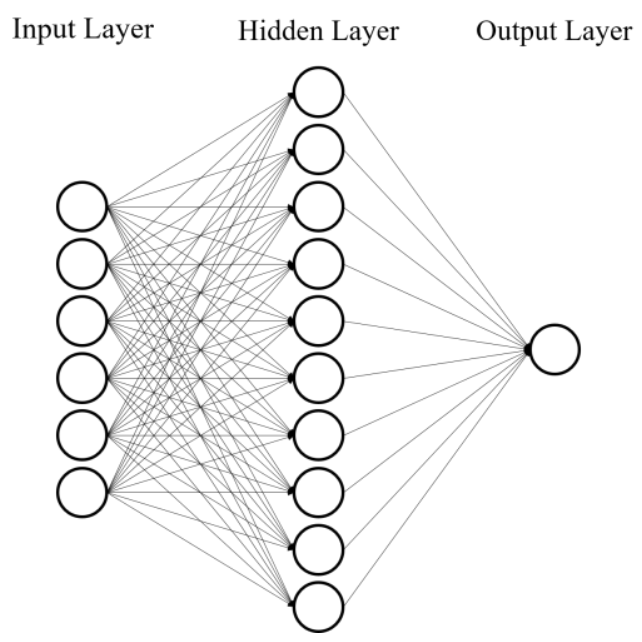

Figure 3. Initial ANN model

Table 3. The variables and values of the input, hidden, and output neurons of the initial ANN model

\begin{tabular}{|c|c|c|}
\hline Layer & Variable & Value \\
\hline \multirow{6}{*}{ Input } & $\begin{array}{c}\text { Outdoor Air Drybulb } \\
\text { Temperature }\left[{ }^{\circ} \mathrm{C}\right]\end{array}$ & $14 \sim 32$ \\
\hline & $\begin{array}{c}\text { Outdoor Air Relative } \\
\text { Humidity [\%] }\end{array}$ & $27 \sim 99$ \\
\hline & $\begin{array}{c}\text { Diffuse Solar Radiation Rate } \\
\text { per Area }\left[\mathrm{W} / \mathrm{m}^{2}\right]\end{array}$ & $11 \sim 450$ \\
\hline & $\begin{array}{c}\text { Direct Solar Radiation Rate } \\
\text { per Area }\left[\mathrm{W} / \mathrm{m}^{2}\right]\end{array}$ & $0 \sim 900$ \\
\hline & $\begin{array}{l}\text { AHU Supply Air } \\
\text { Temperature }\left[{ }^{\circ} \mathrm{C}\right]\end{array}$ & $12 \sim 18$ \\
\hline & $\begin{array}{c}\text { Cooling Coil } \\
\text { Total Cooling Rate [W] }\end{array}$ & $0 \sim 510,000$ \\
\hline \multirow{2}{*}{ Hidden } & Number of Hidden Layer & 1 \\
\hline & Number of Hidden Neurons & 10 \\
\hline Output & $\begin{array}{c}\text { Total Energy } \\
\text { Consumption(Supply Fan, } \\
\text { Relief Fan, Chiller, Chiller2, } \\
\text { Cooling Tower, Chilled } \\
\text { Water Pump, Condenser } \\
\text { Water Pump) [kWh] }\end{array}$ & $4 \sim 100$ \\
\hline
\end{tabular}

As described above, the number of hidden layers and hidden neurons are determined to optimize ANN model. The optimization method was performed by fixing the values of other variables while analyzing the performance of one target, and this study compared the total energy consumption predicted by ANN model with total energy consumption derived from EnergyPlus simulation and set each of the variables as the final target value when $\mathrm{CV}$ (RMSE) value was less than $30 \%$. For example, during the simulation for finding the optimal number of hidden neurons, the number of hidden layers is fixed to the initial value in order to determine the optimal number of hidden neurons by evaluation, and the optimal number of hidden layers was determined in the same way. In this study, the number of hidden neurons and hidden layers were optimized as shown in Table 4, and the lowest CV(RMSE) of $24.04 \%$ was obtained when the number of hidden neurons was 16 and the number of hidden layers was 2 . The optimized ANN model is shown in Figure 4.

Table 4. The CV(RMSE) value(\%) according to the number of hidden neurons and hidden layers

\begin{tabular}{|c|c|c|c|c|c|c|}
\hline \multicolumn{2}{|c|}{ Sort } & \multicolumn{5}{c|}{ Number of Hidden Layer } \\
\cline { 2 - 7 } & 10 & 27.57 & 29.44 & 27.74 & 30.47 & 33.14 \\
\hline \multirow{4}{*}{$\begin{array}{c}\text { Number } \\
\text { of }\end{array}$} & 11 & 29.86 & 30.09 & 27.21 & 26.34 & 32.70 \\
\cline { 2 - 7 } & 12 & 26.17 & 29.87 & 30.81 & 39.16 & 30.24 \\
\cline { 2 - 7 } & 13 & 32.68 & 32.22 & 26.63 & 31.18 & 34.70 \\
\cline { 2 - 7 } & 14 & 29.18 & 27.52 & 33.05 & 38.72 & 29.81 \\
\cline { 2 - 7 } Nidden & 15 & 29.80 & 31.18 & 26.41 & 33.16 & 40.30 \\
\cline { 2 - 7 } Neurons & 16 & 30.25 & 24.04 & 33.09 & 39.36 & 30.35 \\
\cline { 2 - 7 } & 17 & 26.85 & 28.61 & 30.54 & 39.51 & 38.78 \\
\cline { 2 - 7 } & 18 & 25.84 & 27.43 & 26.49 & 35.59 & 29.73 \\
\cline { 2 - 7 } & 19 & 26.82 & 28.80 & 28.70 & 43.28 & 28.28 \\
\cline { 2 - 7 } & 20 & 25.68 & 35.54 & 28.14 & 56.47 & 105.32 \\
\hline
\end{tabular}




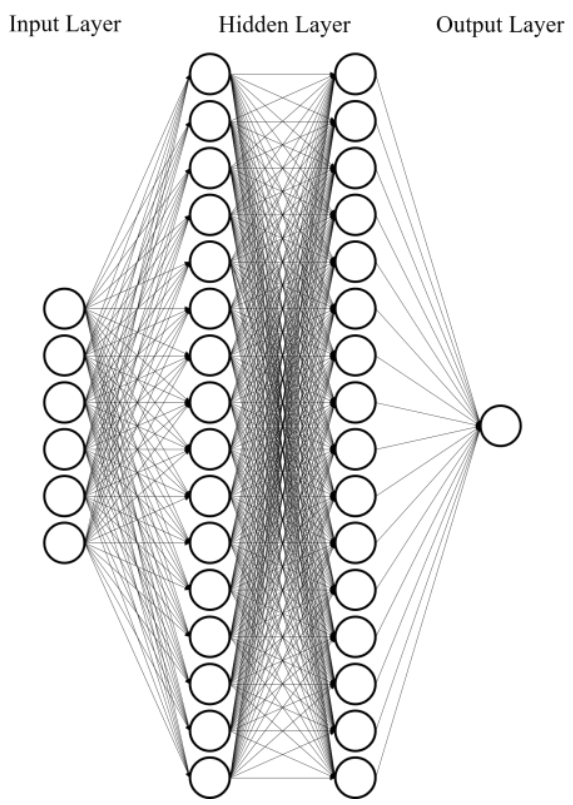

Figure 4. Optimized ANN model

\section{Results Analysis and Discussions}

\subsection{Total energy consumption according to AHU DAT}

In this sub-chapter, a preliminary analysis was performed to investigate how AHU DAT affects the overall system energy performance, before applying ANN based optimized control of AHU DAT. During the analysis, AHU DATs were fixed to constant values during the whole simulation period. Figure 5 shows cooling energy consumption of HVAC system from June 1 to August 31 according to AHU DAT, and cooling energy consumption ratio was high in the order of Chiller1, Chiller2, AHU Supply Fan, Cooling Tower, Condenser Water Pump, Chilled Water Pump, and Relief Fan. As AHU DAT increased to $17^{\circ} \mathrm{C}$, cooling energy consumption gradually decreased and then increased again from $18^{\circ} \mathrm{C}$. The energy consumption was highest at $46,782 \mathrm{kWh}$ when AHU DAT was $12^{\circ} \mathrm{C}$, and energy consumption was lowest at $39,038 \mathrm{kWh}$ when AHU DAT was $17^{\circ} \mathrm{C}$. A significant reduction of approximately $17 \%$ was achieved when $\mathrm{AHU}$ DAT was $17^{\circ} \mathrm{C}$ compared to $12^{\circ} \mathrm{C}$ as the energy consumption of AHU Supply Fan and Relief Fan increased while the energy consumption of other equipment decreased. The Chilled Water Pump showed a very high energy saving as AHU DAT increased, but the impact on the change in energy consumption was minimal because of the low energy consumption. In addition, the energy consumption of Chiller1 and Chiller2, which account for the highest percentage in cooling energy consumption, each showed energy savings of $22 \%$ and $35 \%$ when comparing AHU DAT $12^{\circ} \mathrm{C}$ and $17^{\circ} \mathrm{C}$, confirming that energy consumption was greatly affected by AHU DAT. On the other hand, the energy consumption of AHU Supply Fan and Relief Fan increased as AHU DAT increased, but the share of cooling energy consumption was low compared to Chiller1 and Chiller2 described above. Therefore, compared to AHU DAT $12^{\circ} \mathrm{C}$, which showed the highest total cooling energy consumption, cooling energy consumption effect was excellent as AHU DAT increased up to $17^{\circ} \mathrm{C}$ and significant savings were observed even up to $18^{\circ} \mathrm{C}$.

\subsection{Hourly AHU discharge air temperature control status predicted by ANN model}

Figure 6 shows hourly AHU DAT set-point from 5:00 to 19:00 on June 9 during the analysis period predicted by ANN model. The ANN model of this study combines energy consumption of AHU Supply Fan, Relief Fan, Two Chillers, Cooling Tower, Chilled Water Pump, and

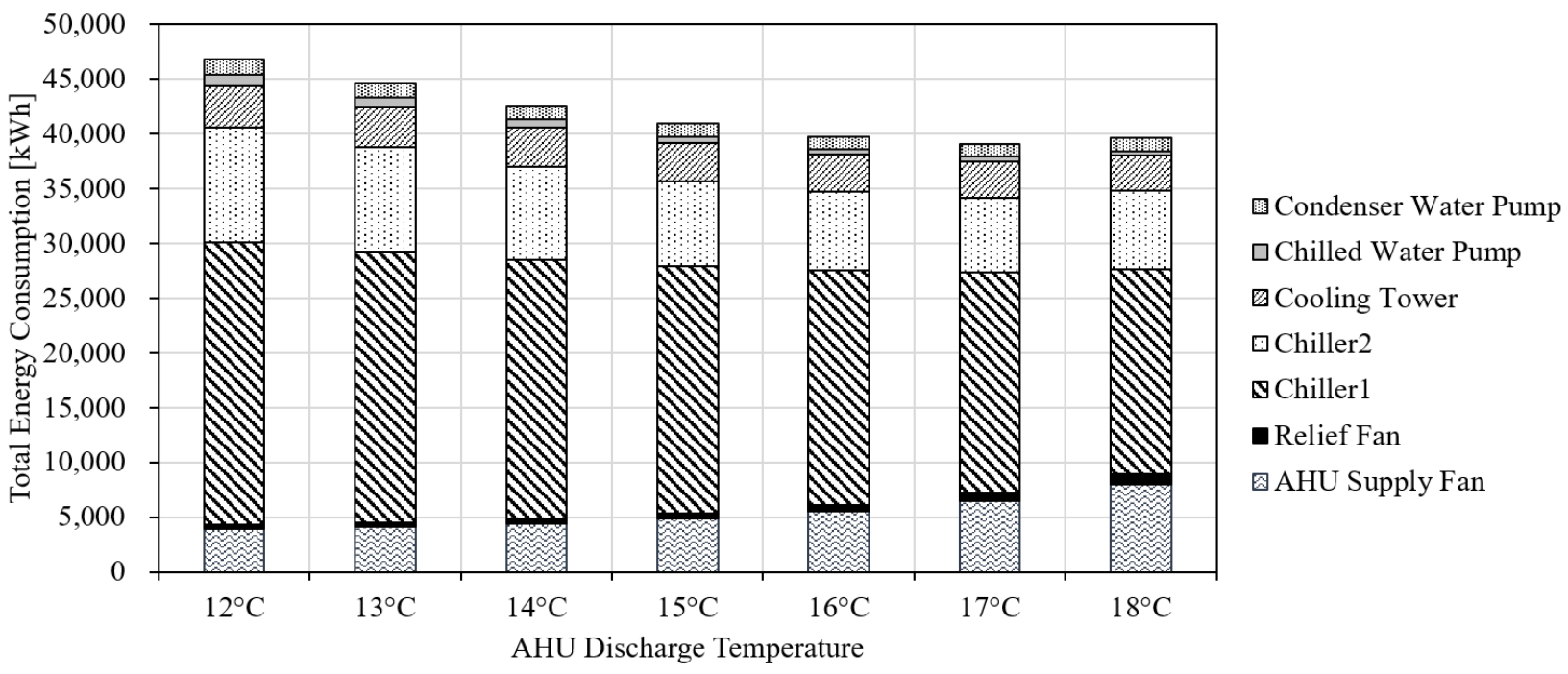

Figure 5. Total cooling energy consumption according to AHU Discharge Air Temperature change 
Condenser Water Pump at each time-step from 5:00 to 19:00(HVAC system operating hours) from June 1 to August 31, and sets the AHU DAT as the optimal AHU DAT when the total cooling energy consumption is the minimum value. As a result, AHU DAT was set to $17^{\circ} \mathrm{C}$, in which total cooling energy consumption is the lowest from 5:00 to 7:00, and was set to $18^{\circ} \mathrm{C}$ from 8:00 to $11: 00$. Then, it was controlled to $15^{\circ} \mathrm{C}$ from $12: 00$ to $13: 00$ as AHU DAT decreased, and was lowered by $1^{\circ} \mathrm{C}$ to $14^{\circ} \mathrm{C}$ from 14:00 to 16:00. From 17:00, AHU DAT was controlled to be gradually higher and then at 19:00, the last time period for operating HVAC system, it was controlled at $18^{\circ} \mathrm{C}$. As a result of comparing energy consumption derived based on AHU DAT on June 9 predicted by the optimal ANN model with fixed control case, it showed energy savings of $21 \%$ compared to the highest energy consumption at $18^{\circ} \mathrm{C}$ on the corresponding day and energy savings of $2 \%$ compared to the lowest energy consumption at $16^{\circ} \mathrm{C}$. Figure 7 shows the cumulative hours of each AHU DAT control. According to the graph, $18^{\circ} \mathrm{C}$, which shows the lowest total cooling energy consumption after AHU DAT $17^{\circ} \mathrm{C}$, accounted for 864 hours out of total 990 hours, followed by 55 hours at $17^{\circ} \mathrm{C}, 22$ hours at $16^{\circ} \mathrm{C}, 19$ hours at $14^{\circ} \mathrm{C}, 15$ hours at $12^{\circ} \mathrm{C}$, 13 hours at $15^{\circ} \mathrm{C}$, and 2 hours at $13^{\circ} \mathrm{C}$.

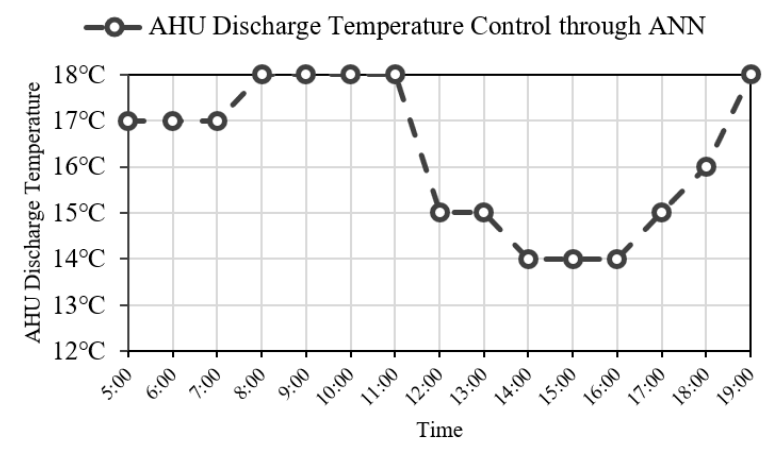

Figure 6. Hourly AHU Discharge Air Temperature control status (June 9)

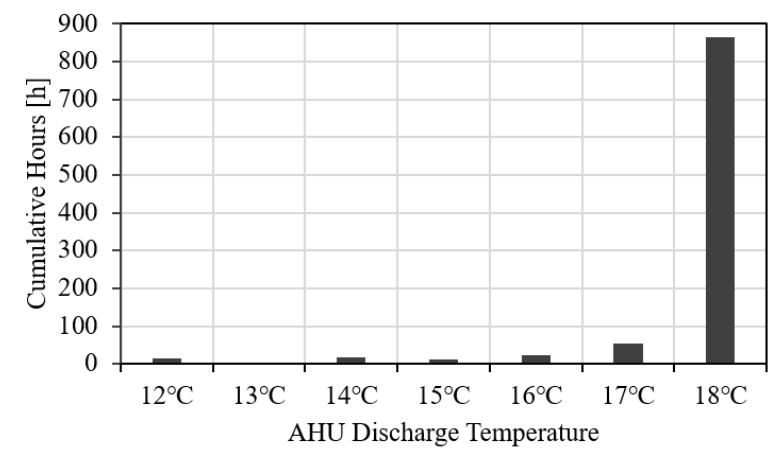

Figure 7. The cumulative hours for each AHU DAT control

\subsection{Chiller energy consumption}

The chiller accounts for the largest portion of total cooling energy consumption. Therefore, reducing energy consumption of the chiller is a key point to reduce the overall cooling energy. Figure 8 shows the total energy consumption of Chiller1 and Chiller2 during HVAC operating hours from 5:00 to 19:00 from June 1 to August 31 when AHU DAT is fixed from $12^{\circ} \mathrm{C}$ to $18^{\circ} \mathrm{C}$ and when the optimal AHU DAT is controlled at each time-step through the optimal ANN model. In the case of Chiller1, energy consumption pattern showed a steady decrease as AHU DAT increased, and Chiller2 showed a steady decrease until AHU DAT increased up to $17^{\circ} \mathrm{C}$, and then increased again from $18^{\circ} \mathrm{C}$. Therefore, among the fixed control cases, total energy consumption of Chiller1 and Chiller2 was the lowest at $25,828 \mathrm{kWh}$ in the case of AHU DAT $18^{\circ} \mathrm{C}$, and Chiller2 was the lowest at $6,803 \mathrm{kWh}$ at $17^{\circ} \mathrm{C}$. When AHU DAT was controlled through the optimal ANN model, the energy savings rate was $30 \%$ higher than that of AHU DAT $12^{\circ} \mathrm{C}$. Compared to AHU DAT $18^{\circ} \mathrm{C}$, Chiller 1 showed a low energy savings of $0.2 \%$, while Chiller 2 showed an energy savings of $8 \%$, resulting in a total chiller energy reduction rate of $2 \%$.

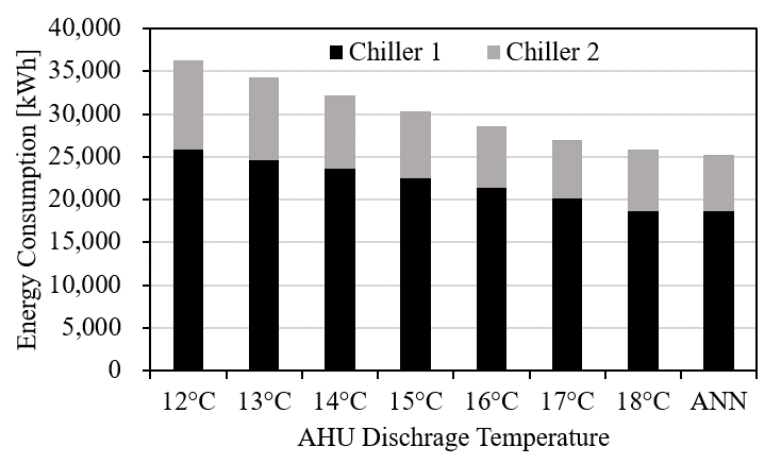

Figure 8. Chiller energy consumption comparison

\subsection{Total cooling energy saving by ANN}

Figure 9 shows total cooling energy consumption of AHU Supply Fan, Relief Fan, Two Chillers, Cooling Tower, Chilled Water Pump, and Condenser Water Pump in each simulated case. The total cooling energy consumption was highest at $46,782 \mathrm{kWh}$ when AHU DAT was $12^{\circ} \mathrm{C}$ because energy consumption of other devices was higher than other cases except for AHU Supply Fan and Relief Fan. The difference in total energy consumption between AHU DAT $17^{\circ} \mathrm{C}$ and $18^{\circ} \mathrm{C}$ was approximately $1.5 \%$ lower at $17^{\circ} \mathrm{C}$. At $18^{\circ} \mathrm{C}$, energy consumption was $39,618 \mathrm{kWh}$ higher than that of $17^{\circ} \mathrm{C}$ due to increased energy consumption of Chiller2 and Condenser Water Pump. However, at $17^{\circ} \mathrm{C}$, energy consumption was $39,038 \mathrm{kWh}$ due to reduced energy consumption of Chiller2 and Condenser Water Pump. The real-time control of AHU DAT through ANN model showed a significant cooling 


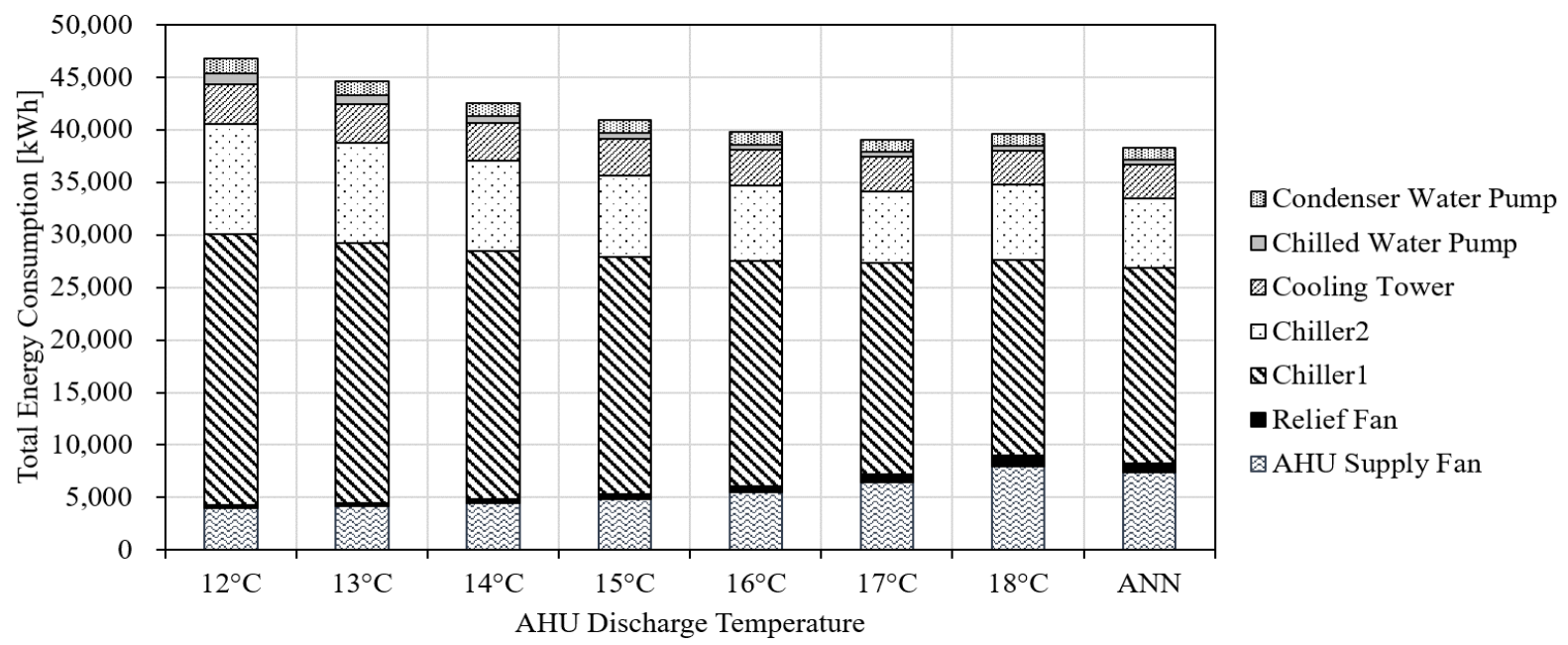

Figure 9. Total cooling energy consumption

energy consumption reduction. Table 5 shows total energy consumption reduction rate of the optimal ANN model when compared to the fixed AHU DATs. As shown in Table 5, cooling energy consumption can be reduced by up to $18 \%$ and at least $2 \%$. Likewise, it is possible to implement real-time optimal control of AHU DAT based on ANN model by minimizing the sum of energy consumption of AHU Supply Fan, Relief Fan, Two Chillers, Cooling Tower, Chilled Water Pump, and Condenser Water Pump in real-time through the learning process of ANN model.

Table 5. Difference in total cooling energy consumption between the optimal ANN model and the fixed AHU DAT control cases

\begin{tabular}{|c|c|}
\hline Case & $\begin{array}{c}\text { Difference between ANN control and fixed AHU } \\
\text { DAT [\%] }\end{array}$ \\
\hline $12^{\circ} \mathrm{C}$ & 18.2 \\
\hline $13^{\circ} \mathrm{C}$ & 14.3 \\
\hline $14^{\circ} \mathrm{C}$ & 10.1 \\
\hline $15^{\circ} \mathrm{C}$ & 6.5 \\
\hline $16^{\circ} \mathrm{C}$ & 3.7 \\
\hline $17^{\circ} \mathrm{C}$ & 2.0 \\
\hline $18^{\circ} \mathrm{C}$ & 3.4 \\
\hline
\end{tabular}

\section{Conclusion}

This study developed an ANN model that can control the optimal AHU DAT in real-time by using the neural network toolbox function embedded in MATLAB and verified its accuracy through $\mathrm{CV}(\mathrm{RMSE})$ analysis. In order to implement ANN model, this study used EnergyPlus and BCVTB platform to implement simulation connected with MATLAB, which can leverage the neural network toolbox functions described previously. From June 1 to August 31, data analysis was performed from 5:00 to 19:00 according to HVAC system schedule and the conclusions are as follows.

Before developing ANN model, this study analyzed total cooling energy consumption from June 1 to August 31 according to AHU DAT. The lower the AHU DAT, the lower the energy consumption, but showed an increasing pattern from $18^{\circ} \mathrm{C}$. The chiller consumed the most energy due to the characteristics of HVAC system during summer. In terms of equipment other than the fan, energy consumption decreased as AHU DAT increased, while AHU Supply Fan and Relief Fan showed an increasing pattern.

Hourly AHU DAT controlled by ANN model from 5:00 to 19:00 during the summer was analyzed. As a result of investigating hourly AHU DAT predicted by ANN model, $18^{\circ} \mathrm{C}$ accounted for the most time at 864 hours out of total cooling time of 990 hours, followed by 55 hours at $17^{\circ} \mathrm{C}, 22$ hours at $16^{\circ} \mathrm{C}, 19$ hours at $14^{\circ} \mathrm{C}, 15$ hours at $12^{\circ} \mathrm{C}, 13$ hours at $15^{\circ} \mathrm{C}$, and 2 hours at $13^{\circ} \mathrm{C}$.

Compared to the fixed control of AHU DAT, the difference in energy consumption between Chiller1 and Chiller2 when AHU DAT is controlled in real-time by applying the optimal ANN model showed 30.4\% lower energy consumption than when AHU DAT was lowest at $12^{\circ} \mathrm{C}, 26.3 \%$ lower than $13^{\circ} \mathrm{C}, 21.5 \%$ lower than $14^{\circ} \mathrm{C}$, $16.6 \%$ lower than $15^{\circ} \mathrm{C}, 11.7 \%$ lower than $16^{\circ} \mathrm{C}, 6.2 \%$ lower than $17^{\circ} \mathrm{C}$, and $2.3 \%$ lower than $18^{\circ} \mathrm{C}$ when AHU DAT was the highest.

Compared to the fixed control of AHU DAT, total energy consumption when AHU DAT is controlled by the optimal ANN model was $18.2 \%$ lower than AHU DAT $12^{\circ} \mathrm{C}, 14.3 \%$ lower than $13^{\circ} \mathrm{C}, 10.1 \%$ lower than $14^{\circ} \mathrm{C}$, $6.5 \%$ lower than $15^{\circ} \mathrm{C}, 3.7 \%$ lower than $16^{\circ} \mathrm{C}, 2.0 \%$ lower than $17^{\circ} \mathrm{C}$, and $3.4 \%$ lower than $18^{\circ} \mathrm{C}$. Therefore, it was possible to reduce cooling energy consumption 
significantly when AHU DAT was controlled in real-time using ANN model.

As a result of using ANN model to optimize AHU DAT control in an office building, this study confirmed that there is certainly the potential to save a considerable amount of cooling energy compared to the simply fixed control method. Therefore, future studies will aim at analyzing higher cooling energy saving effects through simultaneous optimal control of other system control variables such as chilled water temperature, condenser water temperature, and condenser water flow rate, as well as AHU DAT.

This work was supported by the Human Resources Development of the Korea Institute of Energy Technology Evaluation and Planning (KETEP) grant funded by the Korea Government Ministry of Trade, Industry \& Energy (No. 20184030201900)

\section{References}

1. World Meteorological Organization, Greenhouse gas concentrations surge to new record (2017)

2. I. J. Yoon, Issues and Prospects of the Paris Agreement, Han Yang Law Review, 28, 113-144 (2017)

3. Korea Energy Agency, building.energy.or.kr

4. Korea Energy Economics Institute, Energy Consumption Survey 2017 (2018)

5. D. B. Crawley, L. K. Lawrie, F. C. Winkelmann, W. F. Buhl, Y. J. Huang, C. O. Pedersen, R. K. Strand, R. J. Liesen, D. E. Fisher, M. J. Witte, J. Glazer, EnergyPlus: Creating a New-Generation Building Energy Simulation Program, Energy and Buildings, 33, 319-331 (2001)

6. M. R. Hargan, ASHRAE Guideline 14-2002 Measurement of Energy and Demand Savings, American Society of Heating Refrigerating and AirConditioning Engineers Inc, (2002)

7. M. H. Beale, M. T. Hagan, H. B. Demuth, Neural Network Toolbox User's Guide, MathWorks, 72-73 (2018) 